August 2016

\title{
Effectiveness of an interventional program for the management of hypertension through strengthening of the health care delivery system : a pilot study
}

Waris Qidwai

Aga Khan University, waris.qidwai@aku.edu

Khawar Kazmi

Aga Khan University, khawar.kazmi@aku.edu

Kashmira Nanji

Aga Khan University, kashmira.nanji@aku.edu

Sana Anees

Aga Khan University

Follow this and additional works at: http://ecommons.aku.edu/pakistan_fhs_mc_fam_med Part of the Family Medicine Commons

\section{Recommended Citation}

Qidwai, W., Kazmi, K., Nanji, K., Anees, S. (2016). Effectiveness of an interventional program for the management of hypertension through strengthening of the health care delivery system : a pilot study. Middle East Journal of Internal Medicine, 9(2), 3-11.

Available at: http://ecommons.aku.edu/pakistan_fhs_mc_fam_med/85 


\title{
Effectiveness of an Interventional Program for the Management of Hypertension through Strengthening of the Health Care Delivery System: a Pilot Study
}

\author{
Waris Qidwai (1) \\ Khawar Kazmi (2) \\ Kashmira Nanji (3) \\ Sana Anees (4)
}

(1) Dr. Waris Qidwai,Professor and Chairman

Department of Family Medicine, The Aga Khan University, Karachi

(2) Dr. Khawar Kazmi, Professor of Cardiology

Department of Medicine, Aga Khan University, Karachi

(3) Kashmira Nanji, Senior Instructor (Research)

Department of Family Medicine, Aga Khan University, Karachi

(4) Sana Anees, Research Associate

Department of Family Medicine, Aga Khan University, Karachi

Correspondence:

Dr. Waris Qidwai

The Tajuddin Chatoor, Professor and Chairman

Department of Family Medicine, Aga Khan University, Karachi

Stadium Road, PO Box: 3500, Karachi-74800, Pakistan

Tel: 92-21-3486-4842 (Office) 92-3332317836 (Cell)

Email: waris.qidwai@aku.edu

\section{ABSTRACT}

Background: The aim of the study was to assess the effectiveness of an interventional program to improve hypertension management through strengthening of the health care delivery system.

Methods: A pilot study was conducted from February to December 2014 in two off-site Family Medicine clinics of the Aga Khan Hospital Karachi, Pakistan. Patients aged $\geq 40$ years, with known hypertension were included. At the intervention site, Family Physicians were trained; individual and group education sessions were conducted for catchment population, while usual care was provided at the control site. Referral system between primary, secondary and tertiary levels of care was strengthened. Data was entered and analyzed in SPSS version 19. T-test for independent sample was used for comparison between intervention and control groups.

Results: 118 patients were recruited but 90 patients (44 intervention, 46 control group) were included in the final analysis. Mean age of patients in intervention group was $50.5+8.7$ years in comparison to $52.0+8.3$ years in the control group. A statistically significant mean difference was observed in systolic BP control in the intervention group $(140.2+14.6 \mathrm{~mm} \mathrm{Hg})$ after a follow-up of six months. There was a significant difference in the mean scores of satisfaction levels between intervention $(3.9+0.2)$ and control groups $(3.7+0.2, P=0.003)$. Post intervention, $55 \%$ of patients in the intervention group and $39 \%$ in the control group were taking antihypertensive medications regularly.

Conclusion: Intervention at primary care level along with strengthening of the health care delivery system should be undertaken to better manage hypertension.

Key words: Hypertension, Primary Care, Family Physician, Health Care System 


\section{Introduction}

Hypertension is an emerging public health challenge globally; with an increasing prevalence in developing countries.(1) Adverse impact of huge disease burden, arising from hypertensive patients in developing countries, is made worse because of weak health care delivery and lack of resources. Despite such adverse condition awareness, treatment and control of blood pressure among hypertensive patients is improving in these countries. $(2,3)$

Pakistan is a developing country and $33 \%$ of the adult population suffers from hypertension.(4) This huge disease burden puts immense pressure on limited resources. A recent study has reported blood pressure control in accordance to guidelines, among $30.8 \%$ of hypertensive patients in Pakistan.(5) An earlier study has reported younger age and poor awareness about hypertension as factors that adversely affect adherence to antihypertensive medication and blood pressure control among hypertensive patients in Pakistan.(6)

Primary care is the frontline of a health care delivery system where patients are screened and managed for hypertension. It has been shown that strengthening of primary care can result in better blood pressure control among hypertensive patients.(7) It has been reported that training of General Practitioners in management of hypertensive patients results in better blood pressure control among patients in their clinical care.(8)

Limited evidence is available from Pakistan on effectiveness of intervention aimed at strengthening the primary care and health care system to effectively control hypertension. Based on this identified need, we conducted a trial on effectiveness of strengthening the primary care and health care delivery system to effectively control hypertension.

\section{Methods}

\section{Study Settings:}

A quasi-experimental study was conducted in two off-site "Integrated Medical Services" Family Medicine clinics, Aga Khan University Hospital Karachi, Pakistan, from February 2014 to December 2014. Integrated Medical Services (IMS) are community based health care facilities that offer Family Medicine services in addition to diagnostic support.

\section{Patients:}

Individuals aged 40 years or more, visiting the selected IMS centers with knownhypertension or with consistently elevatedBP on two separate visits (mean of last two of three measurements of systolic pressure $\geq 140 \mathrm{~mm} \mathrm{Hg}$ or mean diastolic pressure $\geq 90 \mathrm{~mm}$ $\mathrm{Hg}$ ) or already receiving treatment, were recruited in the study.

Those patients who require intensive care unit or coronary care unit admissions, or were diagnosed to have cognitive impairment, were agitated due to severe pain, non-resident of Karachi, or having language barrier were excluded from the study.

\section{Intervention}

Intervention arm:

Multiple interventions were used including training of family physicians, patient health education sessions and development of a referral system with secondary and tertiary levels of health care.

Training of Family Physician: Consultant Family Physicians conducted training sessions for Family Physicians regarding hypertension and they were given updated information for its management.

Patient Education Sessions: Patients in the intervention arm were provided with individual counseling during which the participants were given detailed information regarding their disease process, optimum blood pressure levels, lifestyle modification (exercise and diet) and importance of adherence to treatment. Participants were also given written brochures/ pamphlets about hypertension management. The education session was conducted by a Research Medical Officer (RMO) who was trained for this task by a Consultant Physician. The Family Physician also provided customized education to patients according to their needs.

\section{Initiating a Referral system (primary-secondary-tertiary) for hypertension management:}

Primary care: Patients with uncomplicated hypertension were managed by the Family Physician at the IMS clinics. Those with complicated hypertension such as with target organ damage, CVD, CKD or needing more than 3 drugs were referred for secondary care.

Secondary care: Community Health Center, Aga Khan University Hospital served as the secondary care service provider. Patients with CVD, CKD or needing more than 3 drugs, not responding to treatment, or patients with secondary hypertension were referred to tertiary care level.

Tertiary care: Cardiologist at AKU managed secondary, resistant and difficult to treat hypertension. The patients were then referred back to the Family Physician at primary care level.

Control Arm: Standard Care: Patients coming to the control clinic of IMS were given usual hypertension care received at the IMS centers.

\section{Outcome Ascertainment:}

The primary outcome was to observe a difference of at least 20 points in the blood pressure levels among the intervention and control groups within 06 months of follow-up. The other secondary outcomes of this study were: adherence to life style modification (exercise, and medication) by the patients. Cost of hypertension treatment, this included: cost of medication (selfreport by patient), cost of physician visit (clinic data), and cost of laboratory work. Patient Satisfaction to the care was inquired through PSQ-18. (9) It is a short form of the PSQ III which has 
80 questions and includes seven dimensions of satisfaction that is general satisfaction, technical quality, interpersonal manner, communication, financial aspects, time spent with doctor, and accessibility and convenience.

Baseline Assessment: Baseline assessment included detailed history, physical examination, laboratory investigations and a care plan.

\section{Follow up visits:}

At 3 and 6 months: Patients in both arms were reassessed at 03 and 06 months intervals and outcome assessment was carried out. The study covered anthropometric measurements, blood pressure assessment and lab investigations. Adherence to medications and life style modification (diet, exercise) were evaluated through self-report and counting of empty medication blisters.

Questionnaire Development: The questionnaire was initially developed in English language and was then translated into local language and back translated in English. The consistency in the back translated questionnaire was checked by the principal investigator/co-investigators, and any discrepancies found were removed.

Ethical Consideration: The study was reviewed and approved by the Ethical Review Committee of Aga Khan University. The trial was also registered at clinical trial.gov (NCT02186067).

Written Informed Consent was obtained from all participants after explaining to them about the study protocol. All study personnel were trained in procedures for maintaining patient confidentiality. No personal identifiers were used in any report or publication arising from this study.

\section{Statistical Analysis:}

Sample Size: The study was designed to enroll 90 patients (45 patients in each group). This number of patients would provide the study with the ability to detect a 20 percent difference among groups (treatment and control) in six months with a power of $80 \%$. The proportion in the treatment group is assumed to be 0.60 . The sample size was calculated using NCSS PASS.

Analysis: Data was entered and analyzed in SPSS version 19. For continuous variables (e.g. SBP, DBP) means with standard deviations (SDs) were reported. For dichotomous data, we calculated proportions. Independent t-test was used to identify the difference in mean BP level among intervention and control groups. Chi-square test was applied to observe effect of intervention on exercise habits and medication adherence. Items within each scale of PSQ 18 are averaged after scoring. These scale scores represent the average for all items in the scale that were answered. High scores on PSQ 18 reflect satisfaction with medical care. Intention to treat analysis was carried out for all participants.

\section{Results}

A total of 126 (intervention: 62, control: 64) patients were recruited at baseline, out of which 90 patients (44 intervention group, 46 control group) completed the study protocol and were included in the final analysis. The overall attrition rate was $29 \%$ in the control group and $19 \%$ in the intervention group (Figure 1 - next page).

The mean age of the participants in the intervention group was $50.5+8.7$ years and $52.0+8.3$ years in the control group. The socio demographic characteristics of study participants are given in Table 1 (page 7). Both the study groups had preponderance of female participants (intervention: $61.4 \% \mathrm{v} / \mathrm{s}$ control: $69.6 \%$ ). About $11 \%$ of the participants in the intervention group and $8.7 \%$ in the control group were unable to read or write. Over $80 \%$ of the participants in both the groups had family history of hypertension. Both the study groups were similar in terms of the demographic characteristics such as age, gender, educational status etc.

A statistically significant mean difference of $17.35 \mathrm{~mm} \mathrm{Hg}$ was observed in systolic BP of intervention $(140.2+14.6 \mathrm{~mm} \mathrm{Hg})$ and control group $(157.6+17.5)$ after a follow-up of 06 months (Table 2 - page 8). Likewise a 7 point difference was observed in diastolic BP (intervention: $86.0+6.6$ ). Changes in blood markers of blood pressure control at six months follow-up are presented in Table 2 .

Satisfaction with services was assessed through PSQ-18 scale which has seven dimensions. There was a significant difference in the mean scores of satisfaction levels between intervention $(3.9+0.2)$ and control groups $(3.7+0.2)$ with a P-value of 0.003 (Table 3).

The average monthly cost of hypertension treatment was PKR.653 + 376 among the intervention and PKR.753 + 817 in the control group. This difference however, was not statistically significant $(\mathrm{P}=0.45)$.

The majority (54.6\%) of the patients in the intervention group were taking antihypertensive medications regularly, in comparison to $39.2 \%$ of the patients in the control group $(\mathrm{P}=0.001)$. About $50 \%$ of the participants in the intervention group started some level of exercise (at least thrice a week for 30 minutes) after the intervention (Table 3 - page 9). 
Figure 1: Flow of Study participants

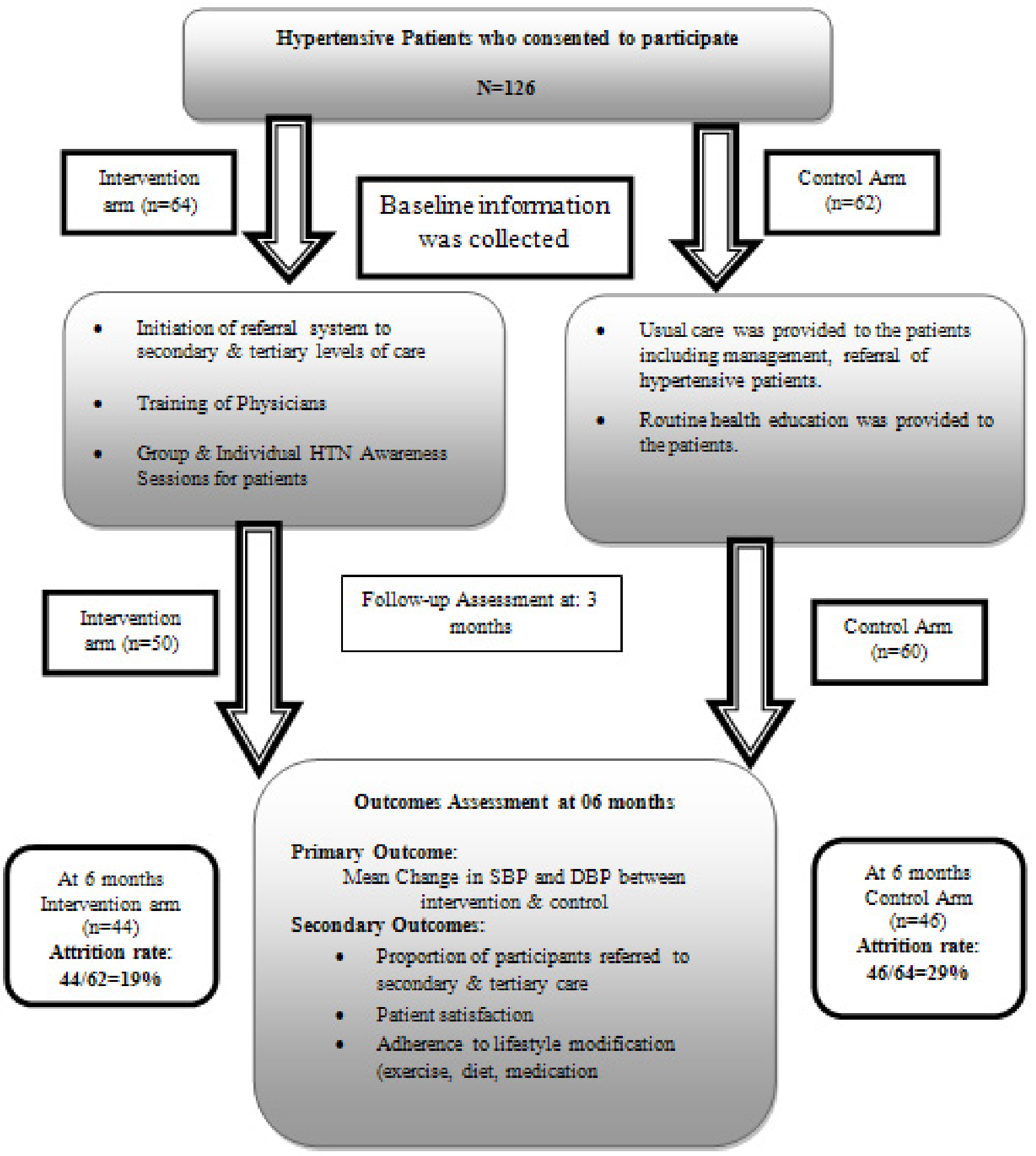


Table 1 : Descriptive Characteristics of Intervention and Control Groups

\begin{tabular}{|c|c|c|c|}
\hline Characteristics & Intervention ( $\mathrm{n}=44$ ) & Control $(n=46)$ & *P-value \\
\hline Age & $50.5 \pm 8.7$ & $52.0 \pm 8.35$ & 0.34 \\
\hline \multicolumn{3}{|l|}{ Gender } & \multirow{3}{*}{0.41} \\
\hline Female & $27(61.4)$ & $32(69.6)$ & \\
\hline Male & $17(38.6)$ & $14(30.4)$ & \\
\hline \multicolumn{3}{|l|}{ Marital Status } & \multirow{3}{*}{0.75} \\
\hline Married & $39(88.6)$ & $39(84.8)$ & \\
\hline Widowed & $5(11.4)$ & $7(15.2)$ & \\
\hline \multicolumn{4}{|l|}{ Educational Status } \\
\hline Can't read or write & $5(11.4)$ & $4(8.7)$ & \multirow{4}{*}{0.77} \\
\hline Up to primary & $3(6.8)$ & $6(13.0)$ & \\
\hline Secondary to Intermediate & $18(40.9)$ & $19(41.3)$ & \\
\hline Graduate or above & $18(40.9)$ & $17(37.0)$ & \\
\hline \multicolumn{4}{|l|}{ Current Occupation } \\
\hline Employed & $13(29.5)$ & $12(26.1)$ & \multirow{3}{*}{0.82} \\
\hline House Wives & $25(56.8)$ & $29(63.0)$ & \\
\hline Unemployed & $6(13.6)$ & $5(10.9)$ & \\
\hline \multicolumn{4}{|l|}{ Comorbid } \\
\hline None & $24(54.5)$ & $22(47.8)$ & \multirow{3}{*}{0.81} \\
\hline 1 comorbid & $16(36.4)$ & $19(41.3)$ & \\
\hline More than 1 comorbid & $4(4.1)$ & $5(10.9)$ & \\
\hline \multicolumn{4}{|c|}{ Family History of Hypertension } \\
\hline Yes & $37(84.1)$ & $38(82.6)$ & \multirow{2}{*}{0.85} \\
\hline No & $7(15.9)$ & $8(17.4)$ & \\
\hline \multicolumn{4}{|l|}{ Family History of DM } \\
\hline Yes & $22(50.0)$ & $29(63.0)$ & \multirow{2}{*}{0.21} \\
\hline No & $22(50.0)$ & $17(37.0)$ & \\
\hline \multicolumn{4}{|l|}{ Family History of CVD } \\
\hline Yes & $19(43.2)$ & $24(52.2)$ & \multirow{2}{*}{0.39} \\
\hline No & $25(56.8)$ & $22(47.8)$ & \\
\hline \multicolumn{4}{|l|}{ EverSmoked } \\
\hline Yes & $6(13.6)$ & $4(8.7)$ & \multirow{2}{*}{0.45} \\
\hline No & $38(86.4)$ & $42(91.3)$ & \\
\hline \multicolumn{4}{|l|}{ Currently Smoking } \\
\hline Yes & $5(11.4)$ & $5(10.9)$ & \multirow{2}{*}{0.94} \\
\hline No & $39(88.6)$ & $41(89.1)$ & \\
\hline
\end{tabular}

*P value $=$ chi square $\mathrm{P}$ value, significance kept at $\leq 0.05$ 
Table 2: Intervention and Control Groups at baseline and six months follow-up

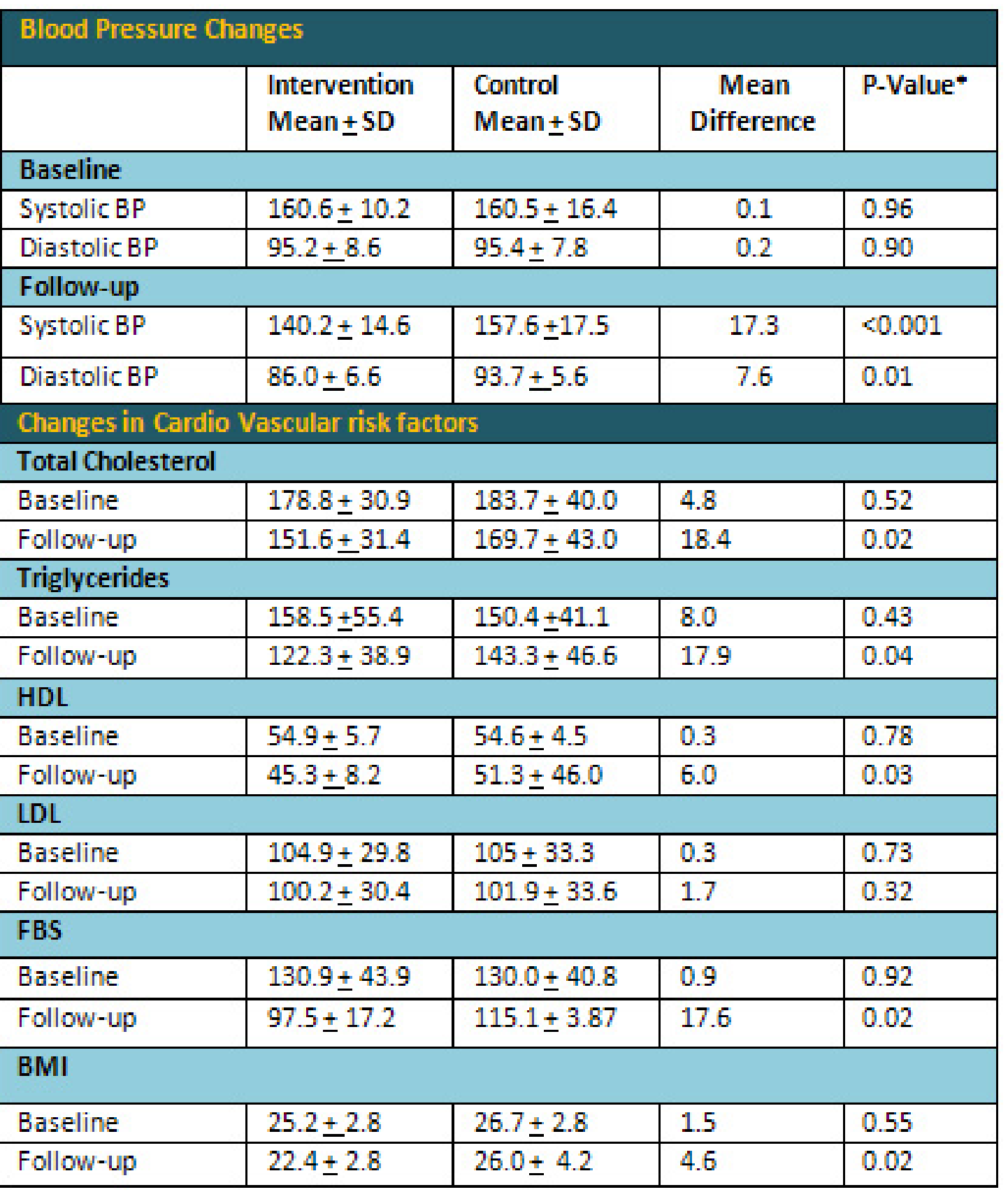

*P value $=$ Two independent $\mathrm{T}$-test $\mathrm{P}$ value, significance kept at $\leq 0.05$ 
Table 3: Participant's Satisfaction and Changes in life style of study participants $(n=90)$

\begin{tabular}{|c|c|c|c|c|}
\hline \multicolumn{2}{|l|}{ Dimensions/Variables } & Intervention & Control & *P-value \\
\hline \multicolumn{2}{|l|}{ Technical quality } & $3.9(0.7)$ & $3.8(0.5)$ & 0.50 \\
\hline \multicolumn{2}{|c|}{ Interpersonal manner } & $3.8(0.4)$ & $3.7(0.4)$ & 0.39 \\
\hline \multicolumn{2}{|c|}{ Communication (doctor-patient) } & $4.0(0.3)$ & $3.7(0.5)$ & 0.02 \\
\hline \multicolumn{2}{|c|}{ Financial aspects } & $4.0(0.5)$ & $3.9(0.5)$ & 0.38 \\
\hline \multicolumn{2}{|l|}{ Time spent for patient } & $3.6(0.7)$ & $3.4(0.6)$ & 0.42 \\
\hline \multicolumn{2}{|l|}{ Convenience } & $3.9(0.8)$ & $3.5(0.7)$ & 0.005 \\
\hline \multicolumn{2}{|l|}{ Accessibility } & $3.9(0.4)$ & $3.9(0.3)$ & 0.65 \\
\hline \multirow[t]{3}{*}{ Overall satisfaction } & \multicolumn{2}{|c|}{$3.9(0.2)$} & $3.7(0.2)$ & 0.003 \\
\hline & \multicolumn{2}{|c|}{$\begin{array}{c}\text { Intervention } \\
\mathrm{N}=44\end{array}$} & \multicolumn{2}{|c|}{$\begin{array}{c}\text { Control } \\
\mathrm{N}=46\end{array}$} \\
\hline & Baseline & Follow-up & Baseline & Follow-up \\
\hline \multicolumn{5}{|l|}{ Exercise } \\
\hline At least three times a week & $10(22.7)$ & $22(50)$ & $11(24.1)$ & $14(30.4)$ \\
\hline No & $34(77.3)$ & $22(50)$ & $35(76.0)$ & $32(69.5)$ \\
\hline P-Value & \multicolumn{2}{|l|}{0.023} & \multicolumn{2}{|c|}{0.62} \\
\hline \multicolumn{5}{|c|}{ Adherence to anti-hypertensive medications } \\
\hline Adherent & $16(36.3)$ & $24(54.6)$ & $14(30.4)$ & $18(39.2)$ \\
\hline Non-Adherent & $28(63.7)$ & $20(45.4)$ & $32(69.6)$ & $28(60.8)$ \\
\hline P-Value & \multicolumn{2}{|c|}{0.04} & \multicolumn{2}{|c|}{0.49} \\
\hline \multicolumn{5}{|l|}{ Change in diet } \\
\hline Some changes & $10(22.7)$ & $21(47.7)$ & $9(19.5)$ & $12(26.0)$ \\
\hline No change & $34(77.3)$ & $23(52.3)$ & $37(80.5)$ & $34(73.9)$ \\
\hline P-Value & \multicolumn{2}{|c|}{0.06} & \multicolumn{2}{|c|}{0.32} \\
\hline
\end{tabular}

*P- Value for difference in satisfaction dimensions by intervention \& control group based on independent-T-test

$* \mathrm{P}$ value $=$ chi square $\mathrm{P}$ value, significance kept at $<0.05$

\section{Discussion}

The primary aim of this study was to evaluate the effectiveness of strengthening the health care delivery system in general and primary care in particular to control epidemic of hypertension. The program included patient group education sessions regarding hypertension and training of Family Physicians along with strengthening of health care delivery system at primary, secondary and tertiary levels. This study has found a favorable impact on lowering Blood Pressure and can therefore be implemented on a larger scale. This is consistent with several similar intervention programs conducted in various countries on varied populations.(10-13)

In this study, lifestyle changes including dietary modification and physical exercise, along with medication adherence, responded favorably to the intervention. In the study, the mean reduction in Systolic Blood Pressure (SBP) at six months follow-up was $17.3 \mathrm{mmHg}$. The findings are consistent with numerous studies where in community based/behavioral intervention had achieved a difference of $15-20$ points in the SBP.(14-19)
This study strengthened the referral system in which the hypertensive patients are managed in primary care settings, and referred to secondary and tertiary care settings if the patients are more challenging or develop complications. In this study, none of the patients were referred to secondary or tertiary care settings. This is most likely because, the Family Physicians were better trained to manage non-complicated cases. Besides that, it can also be due to the fact that patients didn't have hypertension for a longer duration of time so the chances of developing the complications were less; hence they were effectively managed at the primary care level. An additional reason could be small sample size.

In this study, Family Physicians were trained based on latest guidelines to manage hypertension. The group education sessions provided patients with latest information on lifestyle modifications. It is evident that regular visits of patients allow doctors to monitor patients closely and the physicians can encourage self-care among patients, and it can help in better treatment adherence and reduction in blood pressure. $(17,20)$ 
Repeated reminder calls for medication adherence and life style modifications have yielded the desired results observed at six months interval. Regular contact with physicians increases patients comfort level with doctors. This is consistent with our study wherein patients in the intervention group had higher satisfaction scores than control.

It is reported that weight loss leads to blood pressure reduction on a long term basis.(21) In the current study; there was a significant improvement in Body Mass Index (BMI) levels post intervention. This adds to the favorable impact of weight management in the current study on blood pressure control.

Lack of adherence to medications is the common cause for uncontrolled hypertension. Prevalence of non-adherence to hypertensive medication is demonstrated to be a significant for lack of control of blood pressure. (22) This study demonstrates positive impact of intervention that improves adherence to treatment with resultant favorable outcome on blood pressure control.

Significant results were observed in this study, however, the findings of this study should be interpreted cautiously as it was conducted in two study clinics located at a reasonable distance to one another and with less attrition rates observed as compared to other community based intervention trials. Moreover, the lack of blinding of patients and assessor could have resulted in more impact of intervention; as the patients in the intervention arm have received the best possible treatment. Moreover, the follow-up period of this study was only six months so we were unable to determine the long-term sustainability of BP and effect of the interventions on cardiovascular outcomes. Despite these limitations, there is evidence emerging from this pilot study that intervention at primary care level along with strengthening of the health care system results in better blood pressure control among patients with hypertension.

\section{Conclusion}

Hypertension can be effectively managed in the primary care setting through interventions even in developing countries with weak primary health care structure. Such intervention at primary care level along with strengthening of the health care system should be undertaken to better manage hypertension.

\section{Acknowledgement:}

We are grateful to The Aga Khan University Research Council, for providing a grant to conduct this study. We are also grateful to the administration of two study clinics for their cooperation during the implementation of the study. We would also like to thank all the patients for giving their time to this project.

\section{References}

1. Temilolu Olayinka Aje, Michael Miller. Cardiovascular disease: A global problem extending into the developing world. World J Cardiol. 2009 Dec 31; 1(1): 3-10.

2. Ibrahim MM, Damasceno A. Hypertension in developing countries. The Lancet. 2013; 380(9841):611-9.

3. Pereira M, Lunet N, Azevedo A, Barros H. Differences in prevalence, awareness, treatment and control of hypertension between developing and developed countries. Journal of hypertension. 2009; 27(5):963-75.

4. Safdar NF, Bertone-Johnson ER, Cordeiro L, Jafar TH4, Cohen NL. Dietary patterns and their association with hypertension among Pakistani urban adults. Asia Pac J Clin Nutr. 2015; 24(4):710-9

5. Ragot S, Beneteau M, Guillou-Bonnici F, Herpin D. Prevalence and management of hypertensive patients in clinical practice: Cross-sectional registry in five countries outside the European Union. Blood Pressure. 2016 Apr; 25(2):104-16.

6. Hashmi SK, Afridi MB, Abbas K, Sajwani RA, Saleheen D, Frossard PM, et al. Factors associated with adherence to anti-hypertensive treatment in Pakistan. PLoS One. 2007; 2(3): e280.

7. Feng YJ, Wang HC, Li YC, Zhao WH. Hypertension Screening and Follow-up Management by Primary Health Care System among Chinese Population Aged 35 Years and above. Biomed Environ Sci. 2015 May; 28(5):330-40.

8. Jafar TH. Combined patient and GP training best for BP control in Pakistan. PharmacoEconomics \& Outcomes News. 2011; 640:29.

9. Stallard P. Validity and reliability of the Parent Satisfaction Questionnaire. British journal of clinical psychology. 1996;35(2):311-8.

10. Rakotz MK, Ewigman BG, Sarav M, Ross RE, Robicsek A, Konchak CW, et al. A technology-based quality innovation to identify undiagnosed hypertension among active primary care patients. The Annals of Family Medicine. 2014; 12(4):352-8.

11. Look ARG. Long term effects of a lifestyle intervention on weight and cardiovascular risk factors in individuals with type 2 diabetes: four year results of the Look AHEAD trial. Archives of internal medicine. 2010; 170(17):1566.

12. Ogedegbe GO, Boutin-Foster C, Wells MT, Allegrante JP, Isen AM, Jobe JB, et al. A randomized controlled trial of positive-affect intervention and medication adherence in hypertensive African Americans. Archives of internal medicine. 2012; 172(4):322-6.

13. Stevens VJ, Corrigan SA, Obarzanek E, Bernauer E, Cook NR, Hebert P, et al. Weight loss intervention in phase 1 of the Trials of Hypertension Prevention. Archives of internal medicine. 1993; 153(7):849-58.

14. Anchala R, Kaptoge S, Pant H, Di Angelantonio E, Franco $\mathrm{OH}$, Prabhakaran D. Evaluation of Effectiveness and Cost-Effectiveness of a Clinical Decision Support System in Managing Hypertension in Resource Constrained Primary Health Care Settings: Results From a Cluster Randomized Trial. Journal of the American Heart Association. 2015; 4(1):e001213. 
15. Appel LJ, Champagne CM, Harsha DW, Cooper LS, Obarzanek E, Elmer PJ, et al. Effects of comprehensive lifestyle modification on blood pressure control: main results of the PREMIER clinical trial. JAMA: Journal of the American Medical Association. JAMA. 2003; 289(16):2083-93 2003.

16. Bosworth HB, Olsen MK, Neary A, Orr M, Grubber J, Svetkey L, et al. Take Control of Your Blood Pressure (TCYB) study: a multifactorial tailored behavioral and educational intervention for achieving blood pressure control. Patient education and counseling. 2008; 70(3):338-47.

17. Aziz KU. Evolution of systemic hypertension in Pakistani population. Journal of the College of Physicians and Surgeons-Pakistan: JCPSP. 2015; 25(4):286-91.

18. Hasandokht T, Farajzadegan Z, Siadat ZD, Paknahad Z, Rajati F. Lifestyle interventions for hypertension treatment among Iranian women in primary health-care settings: Results of a randomized controlled trial. Journal of research in medical sciences: the official journal of Isfahan University of Medical Sciences. 2015; 20(1):54.

19. Margolis KL, Asche SE, Bergdall AR, Dehmer SP, Maciosek MV, Nyboer RA, et al. A Successful Multifaceted Trial to Improve Hypertension Control in Primary Care: Why Did it Work? Journal of general internal medicine. 2015:1-8.

20. Gwadry-Sridhar FH, Manias E, Lal L, Salas M, Hughes DA, Ratzki-Leewing A, et al. Impact of interventions on medication adherence and blood pressure control in patients with essential hypertension: a systematic review by the ISPOR medication adherence and persistence special interest group. Value in Health. 2013;16(5):863-71.

21. Stevens VJ, Obarzanek E, Cook NR, Lee IM, Appel LJ, West DS, et al. Long-term weight loss and changes in blood pressure: results of the Trials of Hypertension Prevention phase II. Annals of internal medicine. 2001; 134(1):1-11.

22. Raebel MA, Ellis JL, Carroll NM, Bayliss EA, McGinnis $\mathrm{B}$, Schroeder EB, et al. Characteristics of patients with primary non-adherence to medications for hypertension, diabetes, and lipid disorders. Journal of general internal medicine. 2012; 27(1):57-64. 